Proc. Nat. Acad. Sci. USA

Vol. 71, No. 5, pp. 1949-1951, May 1974

\title{
Are Recommended Daily Allowances for Vitamin C Adequate?*
}

\author{
(ascorbic acid/diet)
}

THOMAS H. JUKES

Division of Medical Physics, University of California, Berkeley, Calif. 94720

Communicated by Robert Sinsheimer, January 30, 1974

\begin{abstract}
Recommended daily allowances, U.S.A., for ascorbic acid are several times the minimum daily requirement of about $10 \mathrm{mg}$ to prevent clinical symptoms in adults. The recommended daily allowances reflect the levels of ascorbic acid required to produce tissue saturation in human beings, so that higher doses are promptly excreted in the urine. In various investigations, responses to ascorbic acid were not obtained under conditions where the intake was considerably lower than the recommended daily allowances, but higher than the level needed to prevent clinical symptoms of ascorbic acid deficiency. The human ascorbic acid requirement cannot be calculated by a linear extrapolation from guinea pigs per $\mathrm{kg}$ of body weight because guinea pigs are much smaller than human beings and, hence, their metabolism is more rapid per unit of body weight. Evolutionary loss of ascorbicacid-synthesizing ability may be a neutral change that was incorporated by genetic drift.
\end{abstract}

Great interest in the requirement of human beings for vitamin $\mathrm{C}$ developed in the $1930 \mathrm{~s}$. The interest and activity resulted from the occurrence of scurvy in infants, the synthesis of ascorbic acid, the discovery of simple analytical procedures for it in biological fluids, and the general interest in nutrition and vitamins that expanded in the 1930 s and 1940 s. Preoccupation with ascorbic acid was further stimulated by food shortages in World War II. A voluminous and excellent literature on the requirement for ascorbic acid appeared (1). The research was clinical and biochemical, and it was reported in medical and nutritional journals. The question was reopened by Hodges et al., who used modern clinical, biochemical, and radioisotopic techniques $(2)$.

Two approaches are used in studying the requirement for ascorbic acid and other water-soluble vitamins. The first is to find the minimum daily requirement for preventing clinical symptoms of the specific deficiency. For ascorbic acid, this requirement for adults is about $10 \mathrm{mg}$ or less $(2,3)$. The second procedure is to measure the daily dose needed for saturating the body tissues. A state of tissue saturation should satisfy all the requirements for ascorbic acid, including those in "stressful" situations such as wound-healing (2), but there remains a possibility that ascorbic acid might have useful pharmacodynamic properties at massive dosages. The dose that saturates the tissues is about 60-100 mg daily, depending on body weight (4-9), as shown by rapid excretion of amounts supplied in excess of this dose. Recent studies (2) indicated that, if uptake and utilization are unimpaired, $45 \mathrm{mg}$ daily

*Upon occasion, the PROcendings will publish invited reviews on subjects pertinent to topics of current articles. By the presentation, as in this instance, of an alternative and distinctive point of view, the resolution of controversy may be advanced. should maintain a full body pool, because the subjects used $3 \%$ of their existing body pool daily, and its maximum size was $1500 \mathrm{mg}$.

Recommended daily dietary allowances, U.S.A., based on this, are $40 \mathrm{mg}$ for infants and children under 4 years of age and $60 \mathrm{mg}$ for all other classes (10). Upper limits of 60, 90, and $120 \mathrm{mg}$ in special dietary foods (11) are permitted, respectively, for children under 4 , adults and children 4 or more years of age, and pregnant or lactating women. The recommended allowance for ascorbic acid is, therefore, a multiple of the minimum requirement, so that the "margin of safety" is usually wide. The intake recommended in Canada and the United Kingdom is $\mathbf{3 0} \mathrm{mg}$ for adults, only half the U.S. allowance. Recommended allowances in the U.S.A. are estimated as "sufficiently above the average requirement for particular nutrients to cover the needs of between $95 \%$ and $99 \%$ of the normal healthy population" (12), but it seems unlikely that between $1 \%$ and $5 \%$ of normal healthy persons receiving $60 \mathrm{mg}$ of ascorbic acid daily would be deficient, in view of the finding $(2,13)$ that $45 \mathrm{mg}$ daily should maintain a full body pool. Hodges et al. (13) found that the minimal amount of ascorbic acid necessary to prevent or cure scurvy appeared to be slightly less than $10 \mathrm{mg}$ daily.

The wide margin between the minimum requirement and U.S. recommended allowance for ascorbic acid might tend to increase the consumption of fruits and vegetables beyond the level needed to supply the ascorbic acid requirement. A high intake of such foods could beneficially upgrade the diet with respect to minerals and other vitamins, especially folic acid, which tends to be in short supply. However, there have been objections to the concept that it is necessary to go as high as "tissue saturation" with ascorbic acid for maintenance of health (2). During World War II the average intake of ascorbic acid in England was estimated to be $20 \mathrm{mg}$ daily. There was no evidence of widespread vitamin $\mathrm{C}$ deficiency, and many studies failed to show improvement after daily supplementation. Yudkin (14) found no favorable effect in schoolchildren by feeding $25 \mathrm{mg}$ of ascorbic acid daily for 1 year, as shown by various clinical measurements. No beneficial effects from supplemental ascorbic acid including, in some reports, no effects on absenteeism because of illness, appeared in the following studies: Bransby et al. (15), who studied 1242 schoolchildren for 6 months and 214 adult laboring men; Asher (16), who reported on schoolchildren; Stamm, Macrae, and Yudkin (17), who measured bleeding gums in Royal Air Force personnel as a possible index of ascorbic acid deficiency; and Day and Shourie (18) who worked with East Indian children. 
In view. of these results, and many other attempts to produce beneficial effects by administering vitamin $\mathrm{C}$ to children and other groups of human subjects - with negative findingsthe following statement by Yew (19) seems inappropriate:

41 years have now elapsed since vitamin $C$, ascorbic acid, was identified (1), and it seems that by now medical science should have definite information about the crucial problem of how much of this vitamin human beings-including particularly children-need to promote good health and development. This information would be available by now if consistent scientific effort had been expended to obtain it.

Due, however, to decades of neglect on the part of medical scientists, much practical information about human needs for various nutrients is shrouded in confusion and uncertainty.

The facts are that scientific efforts have been consistentlyand successfully-expended to obtain "definite information" on the vitamin $\mathrm{C}$ requirement of human beings.

Yew (19) also states:

Pauling's suggestion that human needs for this vitamin probably have been underestimated by a factor of 10 or more has frequently been ignored or refuted by rhetoric rather than by sound experimentation.

She based this allegation on Pauling's popular book (20). Pauling (21) estimated that human beings require the ascorbic acid content, $2.5 \mathrm{~g}$, of the arithmetic mean of a list of 110 "natural" foods, calculated from the amount of each food that supplies $2500 \mathrm{kcal}$. The estimate makes the following ass $\mathrm{ump}$ tions. (i) The listed foods were available to primitive man, or his ancestors, during the period that the vitamin $\mathrm{C}$ requirement was being established. However, most of the food plants in Pauling's list are of horticultural origin, especially those that are higher in ascorbic acid such as cultivated peppers (Capsicum), cauliflower, parsley, black currants, broccoli, and kale. (ii) Equal amounts of each food on the list, on a caloric basis, were consumed. However, nuts and grains, which contain little or no ascorbic acid, probably were used more than fruits and leafy plants by primitive humans as a source of calories (22). (iii) No animal foods were consumed. However, human beings are omnivorous, not vegetarian. (iv) The ascorbic acid content of the mixture of foods represents the daily requirement. This assumption seems difficult to justify. Plants contain numerous substances, some of which are nutritionally useful and others that are inert or deleterious at high levels. If an animal is consuming a mixture of plant foods to satisfy the need for calories, the noncaloric ingredients will be ingested at levels that do not necessarily correspond to a quantitative nutritional requirement. Pauling also concludes that the evolutionary loss of ascorbic-acidsynthesizing ability in man "provides strong evidence that the optimum rate of intake by man is about 2 or $3 \mathrm{~g}$ per day or more" (21). But if the need were high, loss of ascorbicacid-synthesizing ability would be disadvantageous! King and Jukes (23) pointed out that loss of ascorbic-acid-synthesizing ability in man was probably a neutral change when it occurred, because primates in "natural" conditions have diets that contain adequate amounts of vitamin $\mathrm{C}$, and that the mutation entered the genome by genetic drift. Humans do not develop scurvy unless they subsist on a diet in which dried or refined foods and grain products predominate. The neutral change becomes detrimental only when this artificial change takes place in the environment. Furthermore, loss of ascorbic- acid-synthesizing ability would be extremely unlikely to take place as an evolutionary change unless the ascorbic acid requirement were comparatively small, for the change wou!d greatly restrict the environmental niche that humans could inhabit if their requirement were high. The worldwide spread of our species to numerous localities where dietary sources of ascorbic acid are sparse or seasonal points to the conclusion that the ascorbic acid requirement is low. Other widely distributed species, such as ruminants and rats, can synthesize ascorbic acid, so their requirements might be higher than ours.

Yew draws conclusions regarding human beings from an experiment in which guinea pigs, 10 animals per group, received various levels of ascorbic acid (19). She measured time of recovery from anesthesia after surgery, falling of scabs, weight gain, and amino-acid analysis of regenerated skin. She concluded that young guinea pigs need about $5 \mathrm{mg}$ of ascorbic acid per $100 \mathrm{~g}$ of body weight, daily. Yew's $t$-tests show that "recovery time from anesthesia" was the only parameter in which the $5 \mathrm{mg}$ level appeared superior to $0.5 \mathrm{mg}$.

Yew's results in Table 1 (19) show that recovery time and best growth before and after surgery occurred in the animals fed Purina chow supplying about $3.3 \mathrm{mg}$, although this group was not treated statistically. The requirement could have been less than this, because such commercial diets are formulated to supply higher levels of the vitamin than are necessary. Young guinea pigs weigh about $1 \%$ as much as young human beings, but metabolism is proportional to body surface area rather than to weight. For example, the food intake for a guinea pig, according to Yew, is $10 \%$ of body weight, and, for a $70-\mathrm{kg}$ man, $2800 \mathrm{kcal}$ would be supplied by $1 \%$ of body weight of food containing $4 \mathrm{kcal} / \mathrm{g}$. Linear extrapolation, on basis of body weight, of guinea pig requirements to human requirements, is, therefore, not justifiable, and, in any case, is clearly unnecessary because there is a vast body of information obtained from first-rate studies with human subjects.

The conclusion drawn by Yew (19) is that "gross uncertainty in human requirements for ascorbic acid prevails in nutritional science." This is not supported by Yew's experiment with guinea pigs, and her conclusion is completely at odds with the results of extensive research on ascorbic acid requirement by numerous competent investigators. The Recommended Daily Dietary Allowances for ascorbic acid for adults have just been reduced from $60 \mathrm{mg}$ to $45 \mathrm{mg}$ by the Food and Nutrition Board, National Research Council, National Academy of Sciences. This reduction reflects an increase in the scientific information on the quantitative need for ascorbic acid.

At high dosage rates, vitamins may have pharmacological properties that are distinct from their nutritional effects; a well-known example is the peripheral vasodilatation produced by large amounts of nicotinic acid (24). Subramanian et al. (25) report that administering large doses of ascorbic acid to guinea pigs under various conditions of stress lowered the increased urinary histamine level, presumably by accelerating the breakdown of histamine.

1. See references and discussion in Sherman, C. C. \& Sherman, H. C. (1937) Annu. Rev. Biochem. 6, 346-353; King, C. G. (1939) Annu. Rev. Biochem. 8, 401-403; Morgan, A. F. (1941) Annu. Rev. Biochem. 10, 371-373; Lanford, C. S. \& Sherman, H. C. (1943) Annu. Rev. Biochem. 12, 411-414; Stare, F. J., Hegsted, D. M. \& McKibbin, J. M. (1945) Annu. Rev. Biochem. 14, 440-443. 
2. Hodges, R. E., Baker, E. M., Hood, J., Sauberlich, H. E. \& March, S. C. (1969) Amer. J. Clin. Nutrit. 22, 535-548.

3. Bartley, W. H., Krebs, A. \& O'Brien, J. R. P. (1953) Med. Res. Council Special Report, Ser. No. 280 (H. M. Stationery Office, London).

4. Todhunter, E. N. \& Robbins, R. C. (1940) J. Nutrit. 19, 263-270.

5. Bessey, O. A. \& White, R. L. (1942) J. Nutrit. 23, 195204.

6. Storvick, C. A. \& Hauck, H. M. (1942) J. Nutrit. 23, 111123.

7. Levcowich, T. \& Batchelder, E. L. (1942) J. Nutrit. 23, 399408.

8. Dodds, M. L. \& MacLeod, F. L. (1944) J. Nutrit. 27, 315318.

9. van Eekelen, M., Heinemann, M. \& van Wersch, H. J. (1936) Acta Brevia Neer. Physiol. 6, 107.

10. Schmidt, A. M. (1973) Fed. Regist. 38, 20717, August 2, 1973.

11. Schmidt, A. M. (1973) Federal Register 38, 20738, August 2 1973.

12. Edwards, C. C. (1973) Federal Register 38, 2145, January 19, 1973.
13. Hodges, R. E., Hood, J., Canham, J. E., Sauberlich, H. E. \& Baker, E. M. (1971) Amer. J. Clin. Nutrit. 24, 432-443.

14. Yudkin, J. (1944) Brit. Med. J. 2, 201-205.

15. Bransby, E. R., Hunter, J. W., Magee, H. E., Milligan, E. H. M. \& Rodgers, T. S. (1944) Brit. Med. J. 1, 77-78.

16. Asher, C. (1944) Brit. Med. J. 2, 213.

17. Stamm, W. P., Macrae, T. F. \& Yudkin, S. (1944) Brit. Med.J. 2, 239-241.

18. Day, C. D. M. \& Shourie, K. L. (1943) Indian J. Med. Res. 31, 153-159.

19. Yew, M. -L. S. (1973) Proc. Nat. Acad. Sci. USA 70, 969972.

20. Pauling, L. (1970) Vitamin C and the Common Cold (W. H. Freeman Co., San Francisco).

21. Pauling, L. (1970) Proc. Nat. Acad. Sci. USA 67, 16431648.

22. Struever, S. (1973) as cited in TIME Magazine, October 19, 1973, p. 123.

23. King, J. L. \& Jukes, T. H. (1969) Science 164, 788-798.

24. Fouts, P. J., Helmer, O. M., Lepkovsky, S. \& Jukes, T. H. (1937) Proc. Soc. Exp. Biol. Med. 37, 405-407.

25. Subramanian, N., Nandi, B. K., Majumder, A. K. \& Chatterjee, I. B. (1973) Biochem. Pharmacol. 22, 167-175. 